\title{
Experimental Study of Performance of Pin Fin Heat Sink under Forced Convection
}

\author{
Authors \\ R. Muthukumarn ${ }^{1}$, R. Rathnasamy ${ }^{2}$, R. Karthikeyan ${ }^{3}$ \\ Department of Mechanical Engineering, Annamalai University, Annamalainagar, Tamil Nadu, India \\ Email: armuthu26@gmail.com
}

\begin{abstract}
-
An experimental investigation was performed to study the heat transfer and pressure loss characteristics in a horizontal rectangular wind tunnel having attachment of cylindrical, grooved cylindrical and perforated pin fins over a horizontal based pin fin assembly. The experiments covered the rates from 2000-25,000 and the clearance ratio $(\mathrm{C} / \mathrm{H})=0.0$. In-line Pin fin arrangements were studied for one constant span wise pitch $\left(S_{x} / d=1.2\right)$ and three different stream wise pitch $\left(S_{y} / d=1.2,2.4\right.$ and 3.6) distance. Nusselt number and pressure drop were considered as performance parameters. The performance of all the pin fins compared to each other. The maximum enhancement in Nusselt number corresponds to the grooved cylindrical fin and the results were matching with previous reports.

Keywords - Pin-fin, duct flow, perforated, Wind Tunnel, Grooved cylindrical, Nusselt number, Reynolds number.
\end{abstract}

\section{INTRODUCTION}

This Heat transfer enhancement strategies are classified in two major categories as active and passive methods. Active methods required external power to enhance heat transfer and passive methods do not require external power. One of the most effective methods in heat transfer enhancement is the use of extended surfaces or fins are example of passive that are commonly used in various types of industrial applications such as heat exchanger, furnace design, electronic cooling devices, thermal regenerators, internal cooling system of gas turbine blades and turbo machines. Shaeri and yaghoubi. ${ }^{[1]}$ Requirement of enhanced heat transfer has been very much essential in electronic and industrial components designing because this may cause severe overheating problems and occasionally leads to failure of the system. Pin fins are cylinders or other shaped elements that are attached perpendicular to a wall. Various parameters characterize the pin fins, such as height, shape, diameter, and height to diameter ratio. Sahin and demir, Tahat et al ${ }^{[2,3]}$. Metzger et al. ${ }^{[4]}$ and Chyu et al. ${ }^{[5]}$ revealed that the pin height-to-diameter ratio, in-line or staggered and fin cross-sectional shape, etc. are crucial parameters in determining the heat transfer and friction factor. Ames et al. ${ }^{[6]}$ studied the local Nusselt number and turbulent flow structure characteristics in a pin fin channel and their study revealed that the unsteadiness in the wakes, the shear layers formed between the wake and the high speed main stream flow. Sara [7] presented the characteristics of heat transfer and friction and analyzed the convective heat transfer through a rectangular channel with pin fins of square cross sectional and attached over a flat surface; the pin fins were arranged in a staggered manner, with varied clearance ratios $\mathrm{C} / \mathrm{H}$. Chang et al. ${ }^{[8]}$ investigated the effects of pin-tip leakages on the end wall heat transfer and entry-to-exit pressure drop performances in the pin-fin channel. They found that the channel pressure drops decrease significantly with moderate heat transfer reductions by opening small gaps between the pin-tips and the channel end wall. Jubran et al. ${ }^{[9]}$ reported on an experimental investigation to study the effects of shroud clearance, optimum inter-fin spacing in both span wise and stream wise directions. In a study performed by Tahat et al. ${ }^{[10]}$ in a channel with rectangular cross section equipped with needle fins, the effects of the distance between fins, the space above them and their in-line and staggered arrangement on heat transfer were investigated experimentally. Shaeri and yaghoubi ${ }^{[11]}$ investigated thermal performance of three dimensional 
incompressible laminar flow from heat sinks by using perforated and solid fins attached on a flat surface are studied numerically. Higher performances for perforated fins are observed and effectiveness increased by increasing number of perforations. sahin and demir ${ }^{[12]}$ Studied heat transfer enhancement and pressure drop of perforated pin fins. Enhancement effectiveness varied between 1.1 and 1.9 depending on the clearance ratio and inter fin spacing ratio and optimum design parameters and level were investigated. Ganesh Murali et al. ${ }^{[13]}$ examined the transfer of heat and mass in the radiating type of pin fin with reference to the array pattern in a rectangular channel. The experimental investigation on the grooved type of flat fin, conducted by Ashish and Anil. ${ }^{[14]}$ signified the forced convection in exposing the characteristics of the heat transfer. Jaideep et al. ${ }^{[15]}$ In this study heat transfer enhancement mechanisms are evaluated for the hot side of a TEG system generating power from waste heat in automobile exhaust gases. The use of pin fins was examined, as they are a common and effective way to increase heat transfer in a channel. Meriam et al. ${ }^{[16]}$ Investigated staggered arrays having a geometry of $\mathrm{S}_{\mathrm{x}} / \mathrm{d}=2.5$ and $\mathrm{H} / \mathrm{d}=2$ it was reported that end wall heat transfer and pressure loss measurement. The friction factor is decreasing with increasing spacing.

The review of the literature showed a variety of modifications and the alterations of the fins by introducing the holes, slits and struts, which enhanced the heat transfer. Application of perforation and grooves on the fin surface is justifiable not only because of material saving but also due to ease in manufacturing and cost. In the present work involves experimentally investigated heat transfer and friction loss characteristics for in line pin fin array of cylindrical, grooved cylindrical and perforated fins in a rectangular channel with considering different geometric and flow parameters.

\section{EXPERIMENTAL SETUP}

The schematic diagram of the experimental setup is shown in Fig. 1. This experimental setup consisting of a wind tunnel, pin fin assembly, heater unit and data unit. The working an open circuit suction mode wind tunnel was used for this investigation.

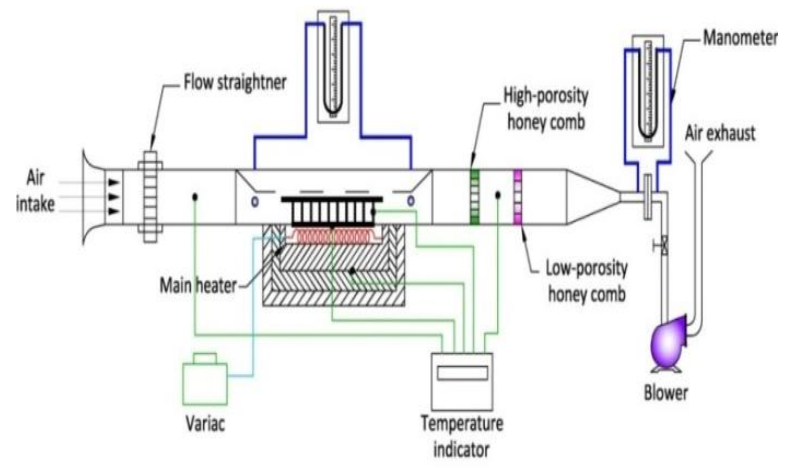

Fig. 1 Line diagram of Experimental setup

\section{A. Wind tunnel:}

Wind tunnel designed of $19 \mathrm{~mm}$ thick plywood and the total length of the tunnel is $2 \mathrm{~m}$ with constant internal width of $150 \mathrm{~mm}$. centrifugal blower supplies air to the test section with required flow rate controlled by operating gate valve. The power was capable of providing a maximum flow rate of 0.242 $\mathrm{Kg} / \mathrm{sec}$. The heated air from the pin fin assembly was passed through an insulated chamber, were mixing was accomplished by two cardboard honeycombs mounted perpendicular to the flow stream, one being relatively low porosity and the other of higher porosity. A differential manometer was employed to measure the pressure drop across calibrated orfice plate to indicate mass flow rate of air.

\section{B. Pin-fin assembly:}

It consists of rectangular base having dimensions are $250 \mathrm{~mm}$ length, $145 \mathrm{~mm}$ width and $25.4 \mathrm{~mm}$ thickness. The tested fins and rectangular base plate were made from duralumin because of consideration of conductivity, machineability and cost.

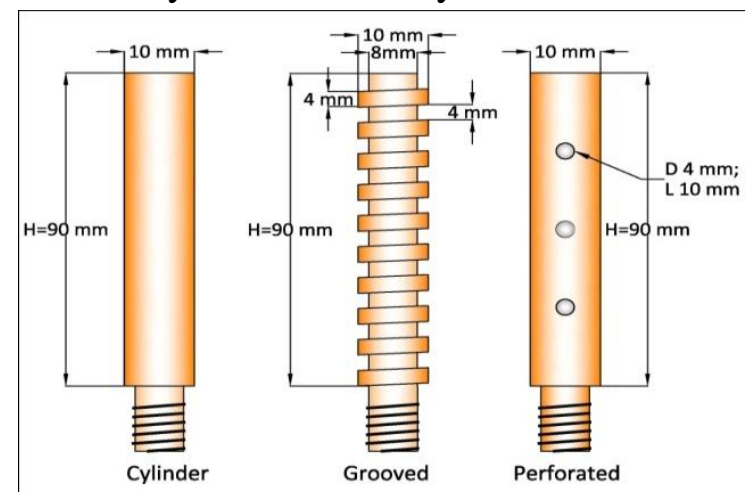

Fig. 2 (a) Cylindrical Fin (b) Grooved cylindrical Fin (c) Perforated Fin 
The array cylindrical fins diameter $10 \mathrm{~mm}$ and height $90 \mathrm{~mm}$ size, the grooved cylindrical fins diameter of $10 \mathrm{~mm}$ with height $90 \mathrm{~mm}$ size. The cylindrical fin was subsequently grooves of diameter $2 \mathrm{~mm}$ with height $4 \mathrm{~mm}$ sizes are formed over the surface by machining. The perforated fins at the 19.5 $\mathrm{mm}$ from bottom tip of those by a $4 \mathrm{~mm}$ diameter drill bit. The values of the relative stream wise pitch $\left(\mathrm{S}_{\mathrm{y}} / \mathrm{d}=1.2,2.4,3.6\right)$ and the relative span pitch $\left(\mathrm{S}_{\mathrm{X}} / \mathrm{d}\right.$ $=1.2)$ were kept constant. The clearance ratio $(\mathrm{C} / \mathrm{H}=0.0)$ between the tips of the pin-fins and shroud the pin fins are attached on the upper surface of the base plate. The pin fins can be easily removed and replaced with studs made from the same as the assembly base.

\section{Heater unit}

The heating unit mainly consisted of an electrical heater, the heat exchanger was heated uniformly by plate heater having of $1500 \mathrm{~W}$, the lower horizontal surface and sides of the heater block were insulated thermally with $80 \mathrm{~mm}$ thick mineral wool blankets. The whole system of heat exchanger base and heater with associate thermal insulation was located in and protected by a well fitting open top wooden box.

\section{Data unit}

The steady state temperature at the rectangular base plate of the pin fin array are recorded using a set of nine copper-constant thermocouples embedded and appropriately distributed, within the rectangular base and average of these readings. The inlet and outlet air stream in the wind tunnel duct were measured using eight thermocouples 6 RTD. Section of the channel was measured using U-tube manometer. The duration to reach the steady state condition was about 1-2 hours depending upon the experimental conditions.

Geometrical characteristics of the pin fins are given in Tables
Table 1. Experimental Parameters For Pin-Fin and Their Values

\begin{tabular}{|l|l|l|}
\hline Parameters & $\begin{array}{l}\text { Minimum } \\
\text { value }\end{array}$ & $\begin{array}{l}\text { Maximum } \\
\text { value }\end{array}$ \\
\hline Spacing of the pin fin $\left[\mathrm{S}_{\mathrm{x}}\right]$ & $12 \mathrm{~mm}$ & $12 \mathrm{~mm}$ \\
\hline Spacing of the pin fin $\left[\mathrm{S}_{\mathrm{y}}\right]$ & $12 \mathrm{~mm}$ & $36 \mathrm{~mm}$ \\
\hline Rate of flow $[\mathrm{m}](\mathrm{kg} / \mathrm{s})$ & 0.069 & 0.143 \\
\hline Clearance ratio $[\mathrm{C} / \mathrm{H}]$ & 0.0 & 0.0 \\
\hline Fin count $\left[\mathrm{N}_{\mathrm{xy}}\right]$ & 30 & 48 \\
\hline Reynolds number $[\mathrm{Re}]$ & 2000 & 25000 \\
\hline $\begin{array}{l}\text { Diameter of pin-fin [d] } \\
(\mathrm{mm})\end{array}$ & 10 & \\
\hline $\begin{array}{l}\text { Height of pin-fin [H] } \\
(\mathrm{mm})\end{array}$ & 90 \\
\hline $\begin{array}{l}\text { Base plate W } \mathrm{x} \quad \mathrm{L} \\
(\mathrm{mm} * \mathrm{~mm})\end{array}$ & $145 \times 250$ \\
\hline $\begin{array}{l}\text { Base plate temperature } \\
{\left[\mathrm{t}_{\mathrm{b}}\right]\left({ }^{\circ} \mathrm{C}\right)}\end{array}$ & $50 \pm 0.25$ \\
\hline
\end{tabular}

Table 2. Distance Between Pin-Fins and Number of Pin-Fins

\begin{tabular}{|l|l|l|l|l|l|l|l|l|l|}
\hline \multirow{2}{*}{ Configuration } & \multicolumn{4}{|l|}{$\mathrm{S}_{\mathrm{y}} / \mathrm{d}=1.2$} & \multicolumn{3}{l|}{$\mathrm{S}_{\mathrm{y}} / \mathrm{d}=2.4$} & \multicolumn{3}{l|}{$\mathrm{S}_{\mathrm{y}} / \mathrm{d}=3.6$} \\
\cline { 2 - 10 } & $\mathrm{N}_{\mathrm{x}}$ & $\mathrm{N}_{\mathrm{y}}$ & $\mathrm{N}_{\mathrm{t}}$ & $\mathrm{N}_{\mathrm{x}}$ & $\mathrm{N}_{\mathrm{y}}$ & $\mathrm{N}_{\mathrm{t}}$ & $\mathrm{N}_{\mathrm{x}}$ & $\mathrm{N}_{\mathrm{y}}$ & $\mathrm{N}_{\mathrm{t}}$ \\
\hline Cylindrical & 6 & 8 & 48 & 6 & 6 & 36 & 6 & 5 & 30 \\
\hline $\begin{array}{l}\text { Cylindrical } \\
\text { with groove }\end{array}$ & 6 & 8 & 48 & 6 & 6 & 36 & 6 & 5 & 30 \\
\hline
\end{tabular}

\section{DATA REDUCTION}

The steady state heat transfer from heated surface can be expressed as follows

$$
Q_{\text {tot }}=Q_{c}+Q_{\text {rad }}+Q_{\text {losses }}
$$

In similar to that followed by Naik et al. ${ }^{[17]}$ and Tahat et al. ${ }^{[18]}$ they conducted experiments and fin arrays are comparable and reported that the heat loss capabilities of the fin array less than 5\%. Although in the present operating conditions together with the fact that the test section is well insulated and assuming the loss is very minimum, eqn. (1) is given as,

$$
Q_{c}=m C_{p}\left(t_{\text {out }}-t_{\text {in }}\right)
$$

The steady state convection heat transfer rate from test can be given by

$$
Q_{c}=h A_{s}\left[t_{b}-\left(\frac{t_{\text {in }}+t_{\text {out }}}{2}\right)\right]
$$

Where, $t_{b}$ is the average temperature at center location on the base assembly, $t_{\text {in }}$ and $t_{\text {out }}$ are the air flow temperatures and $A_{s}$ is the total test surface area, which can be expressed as, 
$A_{s}=W L+\pi D H N_{\text {total }}$

The average convective heat transfer coefficient can be calculated by combining eqns. (2) and (3):

$$
h=m C_{p} \frac{\left(t_{\text {out }}-t_{\text {in }}\right)}{A_{s}\left[t_{b}-\left(\frac{t_{\text {in }}+t_{\text {out }}}{2}\right)\right]}
$$

Under the present operating conditions together with the fact that the test section was well insulated, the free flow area $A_{f f}$ is calculated as,

$$
A_{f f}=W(H+C)-N_{X} H d
$$

The average convection heat transfer coefficient may also be presented in terms of average Nusselt number which can be evaluated from

$$
N u=\frac{h D_{h}}{k}
$$

The motion of the heat transfer medium can be characterized by its Reynolds number $(\mathrm{Re})$ is defined in the conventional way as,

$R e=\frac{G d}{\mu}$

Where, $G=\frac{m}{A_{f f}}$ Is the mass flux

\section{COMPARISON WITH OTHER HEAT TRANSFER CORRELATIONS}

It is customary to present heat transfer data in terms of Nusselt number variation against Reynolds number. For the present work one such plot is given in Fig. 4 it is clear that the Nusselt numbers arrived at are increasing with Reynolds number. In order to validate the data previous work are being compared. The present results are closer to and higher than the result of Tahat et al. ${ }^{[14]}$ and Jubran et al. ${ }^{[15]}$ within the range of experimental conditions.

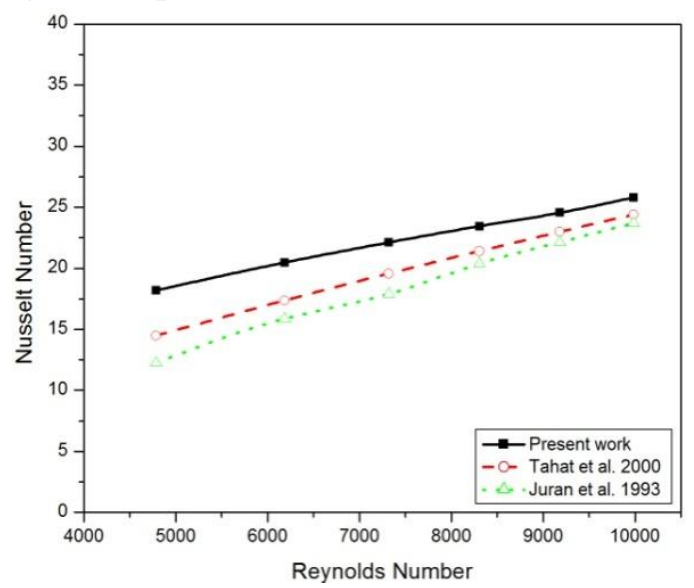

Fig. 3 Plot of Nusselt number Vs Reynolds number (with other correlation)

\section{RESULTS AND DISCUSSIONS}

In this section result from the experiments for different pin fins configuration with Reynolds number are presented for $\mathrm{S}_{\mathrm{x}} / \mathrm{d}=1.2$ and $\mathrm{S}_{\mathrm{y}} / \mathrm{d}=1.2,2.4$ and 3.6.heat transfer and pressure loss measurements of various pin-fin geometries have been explored by carrying out experiments on a test setup that has been designed.

\section{A. Heat transfer rate}

Heat transfer rate as function of Reynolds number for different fin types in Fig. 4 it is seen from this figure the heat transfer rate increase in flow Reynolds number irrespective type of fin. The heat transfer enhancement in pin fin arrays is achieved by introducing turbulence (flow re-attachment or delay separation) Fig. 4 shows the pin-fin profile shape (cylindrical, grooved cylindrical and perforated) influence on heat transfer enhancement. Despite that the foretold three pin fin profile unique contact surface area, the grooved cylindrical fins perform better than cylindrical and perforated as well. Heat transfer rate increases with minimizing inter fin distance in stream wise direction $\left(S_{y} / d\right)$. The heat transfer is found to be increased in the order of cylindrical, perforated and grooved cylindrical fin.

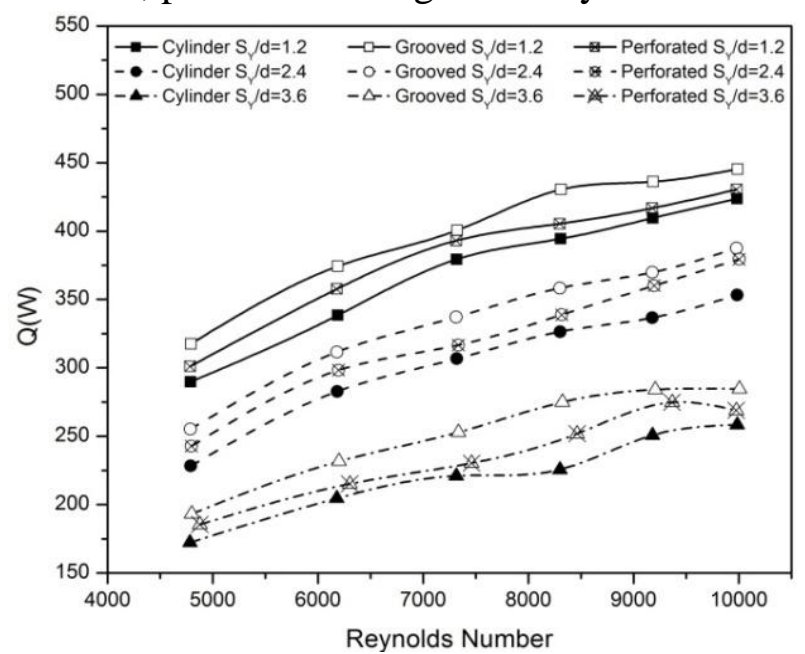

Fig. 4 Effect of pin-fin shape on $\mathrm{Q}_{\text {out }}$ for $\mathrm{S}_{\mathrm{x}} / \mathrm{d}=1.2$

\section{B. Nusselt number}

Fig. 5 shows the variations of Nusselt number with change in the values of Reynolds number for different pin-fin geometries. It can be seen from Fig. 5 that the Nusselt is increases with an increase the value of Reynolds number for all the fin geometries. Figure5 reveal that the Nusselt number of the grooved cylindrical geometries is always higher than 
that of the cylindrical and perforated configuration that have the same span wise, stream wise spacing and same heat transfer area.

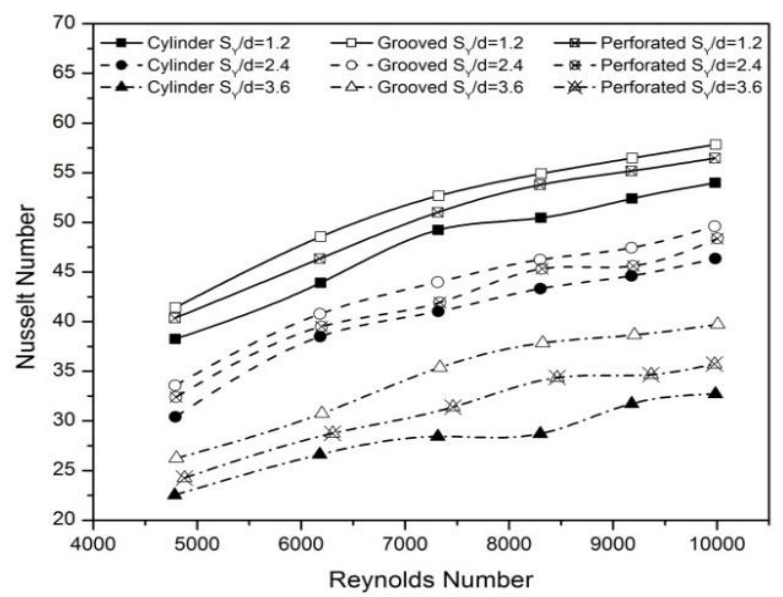

Fig. 5 Effect of pin-fin shape on $\mathrm{Nu}$ for $\mathrm{Sx} / \mathrm{d}=1.2$

\section{Friction factor}

Fig. 6 depicts the friction factor as a function of Reynolds number, the experimental pressure drop over the test section in the fixed duct was measured under the heated flow conditions. It is not uncommon that the flow resistance is an important aspect in heat transfer in order to have minimum pumping power as constraint. The cylindrical pin fins have smaller pressure drops at higher inter fin space ratio $\left(\mathrm{S}_{\mathrm{y}} / \mathrm{d}\right)$ than perforated and grooved cylindrical. The result show that the pumping power generally decreases as $S_{\mathrm{y}} / \mathrm{d}$ increases.

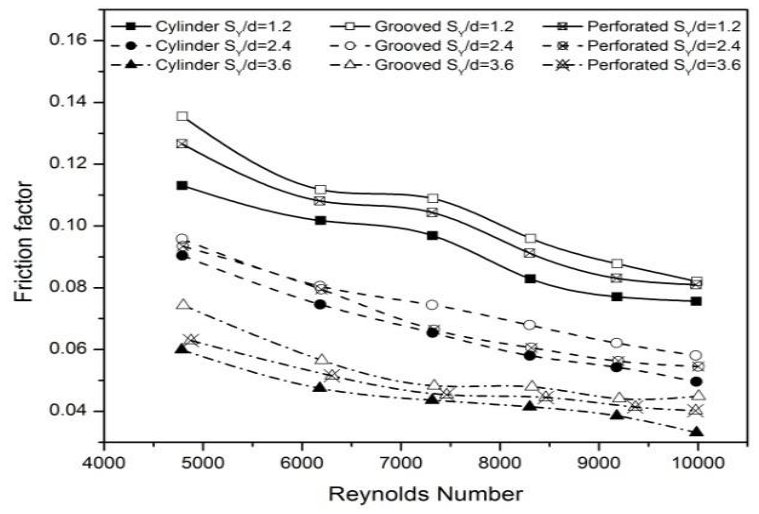

Fig. 6 Plot of 'f' Vs Reynolds number for $\mathrm{Sx} / \mathrm{d}=1.2$

\section{CONCLUSIONS}

In this study, convective heat transfer and pressure drop in a heat exchanger with different pin-fin arrays were studied experimentally. The performance of the pin-fin geometries and span wise pitch, the stream wise pitch were examined. The $S_{y} / d$ values of 1.2 , 2.4 and 3.6, while keeping $S_{x} / d=1.2$ constant. The performance of heat transfer and friction characteristics was determined. The following conclusions were drawn from the results of the present work.

A significant jump in heat transfer is registered pinfins for all the values of Reynolds number. Grooved cylindrical fin geometries out performs compared to cylindrical and perforated fin geometries. In optimal stream wise ratio $(\mathrm{S} / \mathrm{d}=1.2)$ to enhance the heat transfer rate is observed.

The Nusselt number increased with decreasing inter pin fin space ratio. The highest values of Nusselt number were obtained for the grooved cylindrical fin geometries $\left(\mathrm{S}_{\mathrm{x}} / \mathrm{d}=1.2\right.$ and $\left.\mathrm{S}_{\mathrm{y}} / \mathrm{d}=1.2\right)$. the values of Nusselt number for cylindrical and perforated fins lie very close to each other, irrespective of the change in Reynolds number.

The cylindrical pin fins have smaller pressure drops at higher inter fin space ratio $\left(S_{y} / d\right)$ than perforated and grooved cylindrical. The result show that the pumping power generally decreases as Sy /d increases.

\section{Nomenclature}

A area, $\mathrm{m}^{2}$

C clearance between fin tip and the roof, $\mathrm{mm}$

$\mathrm{C}_{\mathrm{p}} \quad$ specific heat of air, $\mathrm{J} / \mathrm{kg} \mathrm{K}$

$\mathrm{d}$ diameter of the pin-fin, $\mathrm{mm}$

f friction factor

$\mathrm{G} \quad$ mass flux, $\mathrm{kg} / \mathrm{m}^{2} \mathrm{~s}$

$\mathrm{H}$ height of the pin-fin, $\mathrm{mm}$

$\mathrm{K}$ thermal conductivity, $\mathrm{W} / \mathrm{m} \mathrm{K}$

$\mathrm{L} \quad$ length of the base plate, $\mathrm{mm}$

M mass flow rate of air, $\mathrm{kg} / \mathrm{s}$

$\mathrm{N}$ number of pin-fin

$\mathrm{Nu} \quad$ Nusselt number

Q heat transfer rate, $\mathrm{W}$

Re Reynolds number

$\mathrm{S} \quad$ spacing, $\mathrm{mm}$

$\mathrm{T}$ temperature, ${ }^{\circ} \mathrm{C}$

$\mathrm{T}$ temperature, $\mathrm{K}$

$\mathrm{W} \quad$ width of the base plate, $\mathrm{mm}$

\section{REFERENCES}

1. M.R. Shaeri, M.Yaghoubi, Thermal enhancement from heat sinks by using perforated fins. Energy conversion and management.vol.50, pp.1264-1270, 2009. 
2. Bayram Sahin and Alparslan Demir, Thermal performance analysis and optimum design parameters of heat exchanger having perforated pin fins, Energy Conversion and Management.vol. 49, pp.1684-1695,2008.

3. Tahat M., Babus'Haq R.F. \& Probert S.D, Forced Steady-State Convections form pinfin arrays. Applied Energy vol.48, pp.335351, 1994.

4. Metzger, D.E., Fan, C.S. and Haley, S.W, Effects of pin shape and array orientation on heat transfer and pressure loss in pin fin Arrays. J. Eng. for Gas Turbines and Power Vol. 106, pp. 252-257, 1984.

5. M.K. Chyu, Heat Transfer and Pressure Drop for Short Pin-Fin Arrays with Pin-End wall Fillet, Journal of Heat Transfer ASME, Vol.112 pp.926-932, 1990.

6. Ames, F.M. Dvorak, A.L. and Morrow, M.J, Turbulent augmentation of internal convection over pins in staggered pin-fin arrays. J. Turbo machine,vol 127, pp.183-190, 2005.

7. O.N.Sara, Pekdemir T, Yapici S, Yilmaz M, Heat transfer enhancement in a channel flow with perforated rectangular blocks. International Journal of Heat Fluid Flow, vol. 22, pp.509-618, 2001.

8. S.W. Chang, T.L. Yang, C.C. Huang and K.F. Chiang Chang et al. End wall heat transfer and pressure drop in rectangular channels with attached and detached circular pin-fin array. International Journal of Heat and Mass Transfer, 2008.

9. Jubran B.A., Hamdan, M.A. \&Abdualh, R.M., Enhanced heat transfer, missing pin, and optimization for cylindrical pin fin arrays. Trans. ASME, Journal. Heat transfer, vol. 115(3), pp. 576-583, 1993.

10. Tanda G, 2001. Heat transfer and pressure drop in a rectangular channel with diamond shaped elements. International journal Heat and Mass Transfer, vol. 44, pp. 3529-41.

11. M.R. Shaeri, M.Yaghoubi, Thermal enhancement from heat sinks by using perforated fins. energy conversion and management.vol.50,pp.1264-1270. 2009.

12. Sahin, B. and Demir A., Thermal performance analysis and optimum design parameters of heat exchanger having perforated pin fins. Energy Conversion and Management.vol. 49, pp. 1684-1695, 2008.

13. Ganesh Murali J.a, Subrahmanya S. Katte, Experimental Investigation of Heat Transfer Enhancement in Radiating Pin Fin Vol.2, 2008.

14. Ashish Dixit \& Anil Kumar Patil, Heat Transfer Characteristics of Grooved Fin Under Forced Convection, Heat Transfer Engineering,vol. 36,pp.1409-1416, 2015.

15. Jaideep Pandit, Megan Thompson, Srinath and Ekkad, Effect of pin fin to channel height ratio and pin fin geometry on heat transfer performance for flow in rectangular channels. International Journal of Heat and Mass Transfer,vol. 77,pp. 359-368, 2014.

16. Meriam Axtmann, Rico Poser, Jens von Wolfersdorf and Marc Bouchez, End wall heat transfer and pressure loss measurements in staggered arrays of adiabatic pin fins, Applied Thermal Engineering, 2016.

17. S. Naik, S.D, Probert Thermal - Hydraulic Characteristics of a Heat Exchanger: The Vertical Rectangular Fins Being Aligned Parallel to the Mean Air-Flow in the Duct Applied Energy, vol.29 pp.217-252, 1988,

18. Tahat MA, Babus'Hag RF and Probert SD, Forced steady state convections from pin-fin arrays. Appl. Energy, vol 48, pp 335-351, 1994.

19. Tahat M, Kodah ZH, Jarrah BA, Probert SD, Heat transfer from pin-fin arrays experiencing forced convection. Applied Energy, vol. 67(4), pp. 419-42, 2000.

20. Jurban BA, Hamdan MA and Abdullah RM, Enhanced heat transfer, missing pin, andOptimization for cylindrical pin fin arrays. ASME J. Heat transfer, vol. 115, pp.576-583, 1993 